\title{
Neues Jahr, neues Kleid
}

\section{Bruno Kesseli}

Dr. med. et lic. phil., Chefredaktor der Schweizerischen Ärztezeitung

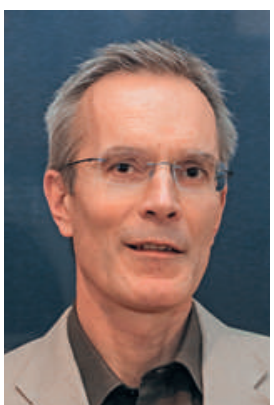

Es ist nicht Mai, und alles neu gemacht haben wir auch nicht. Dennoch dürften Sie, liebe Leserin, lieber Leser, beim Anblick der ersten SÄZ des neuen Jahres gestutzt haben. Schon die Titelseite unterscheidet sich mit dem grossen Foto und der neuen Aufmachung unübersehbar vom bisherigen Auftritt. Und beim Durchblättern müsste sich der Eindruck bestätigt haben, dass optisch ein frischer Wind beim altehrwürdigen "Gelben Heftli» für einige Veränderungen gesorgt hat.

Ja, ein knappes Jahrzehnt nach der letzten sanften Renovation schien es uns an der Zeit, wieder einmal eine "Layoutauffrischung" vorzunehmen. Nicht nur bei der Schweizerischen Ärztezeitung, sondern bei allen Zeitschriften des Schweizerischen Ärzteverlags EMH Media, die nun ein einheitlicheres Erscheinungsbild aufweisen und damit die gemeinsame Herkunft deutlich machen.

«Frisch»: Zwar mag ich dieses verlagsintern im Zusammenhang mit den Layoutanpassungen inflationär gebrauchte Zauberwort bald nicht mehr hören. Die Essenz dessen, was wir angestrebt haben, umschreibt es dennoch ganz gut. Auch wenn letztlich vor allem der Inhalt zählt, ist es eben die «Oberfläche», die als Erstes wahrgenommen wird. Das «Design", die Verpackung, sendet eine Vielzahl von Signalen aus, die vom Betrachtenden - zum grössten

Auch wenn letztlich vor allem der Inhalt zählt, ist es eben die «Oberfläche», die als Erstes wahrgenommen wird.

Teil unbewusst - aufgenommen werden und einen bestimmten Eindruck erzeugen. Dieser sollte im Fall der EMH-Zeitschriften nicht durch Assoziationen wie «altbacken» oder "verstaubt» geprägt sein, sondern der Erwartung Vorschub leisten, auf aktuelle, interessante und für die Ärzteschaft relevante Themen zu stossen, die zugleich anregend und seriös abgehandelt werden.

Dass die angestrebte und nun realisierte Vereinheitlichung des Layouts mit einigen Herausforderungen verbunden war, hängt wesentlich mit der publizistischen Spannweite unserer Zeitschriften zusammen.
Der Bogen reicht vom wissenschaftlichen Journal über die Fortbildungszeitschrift bis hin zu Titeln wie der SÄZ, die sich gestalterisch tendenziell an Publikumszeitschriften orientieren. In diese Vielfalt eine gemeinsame Linie zu bringen, ohne das Korsett für die einzelnen Zeitschriften zu starr werden zu lassen, war keine leichte Aufgabe. Dazu kam die ökonomisch bedingte Vorgabe, mit den Platzressourcen sparsam umzugehen, das heisst pro Seite eine vernünftige Anzahl Zeichen unterzubringen. Das Resultat, ein Kompromiss aus funktionalen, ästhetischen und ökonomischen Ansprüchen, darf sich nach unserer Einschätzung sehen lassen. Wir hoffen, dass Sie nach der meist nötigen Angewöhnungszeit zur selben Einschätzung gelangen.

Bei EMH Media glauben wir (auch) an die Zukunft der Printmedien - nicht aus nostalgischer Schwärmerei.

Die neuen Medien sind in aller Munde. Auch wir sind bestrebt, mit den aktuellen Entwicklungen Schritt $\mathrm{zu}$ halten und beispielsweise die Internet-Auftritte der EMH-Zeitschriften kontinuierlich zu verbessern. Wir freuen uns darüber, wenn gerade die spezifischen Möglichkeiten unserer Online-Zeitschriften rege genutzt werden. Die mit einigem Aufwand verbundene Neugestaltung unserer gedruckten Zeitschriften soll aber auch signalisieren, dass wir bei EMH Media weiterhin (auch) an die Zukunft der Printmedien glauben. Nicht aus nostalgischer Schwärmerei, sondern weil aktuelle medienwissenschaftliche Daten belegen, dass das Leseverhalten in Bezug auf Printprodukte in den letzten Jahren beim Schweizer Publikum stabil geblieben ist - trotz der rasanten Entwicklungen im Bereich der elektronischen Kommunikation.

Das eine tun und das andere nicht lassen, könnte also das Motto für SÄZ-Leserinnen und Leser in Zukunft lauten. Aber natürlich soll auch nach wie vor gelten: Jedem das seine (und jeder das ihre). In diesem Sinne wünsche ich Ihnen, liebe Leserin, lieber Leser, alles Gute zum neuen Jahr. 